\title{
Syntheses of Hydrocarbazole Derivatives via Brønsted acid-Initiated Diels-Alder Cycloaddition/retro-Michael Addition Cascade Reaction of Azepino[4,5-b]indoles and Acrolein
}

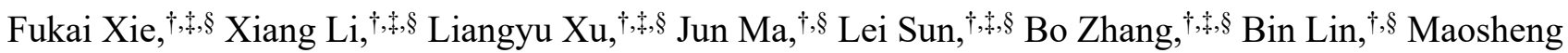
Cheng, ${ }^{\dagger}$, and Yongxiang Liu* ${ }^{* \dagger \dagger, \$ \S}$ $\dagger$ Key Laboratory of Structure-Based Drug Design and Discovery (Shenyang Pharmaceutical University), Ministry of Educa-
tion, Shenyang 110016, P. R. China

* Wuya College of Innovation, Shenyang Pharmaceutical University, Shenyang 110016, P. R. China

$\S$ Institute of Drug Research in Medicine Capital of China, Benxi 117000, P. R. China

Supporting Information Placeholder

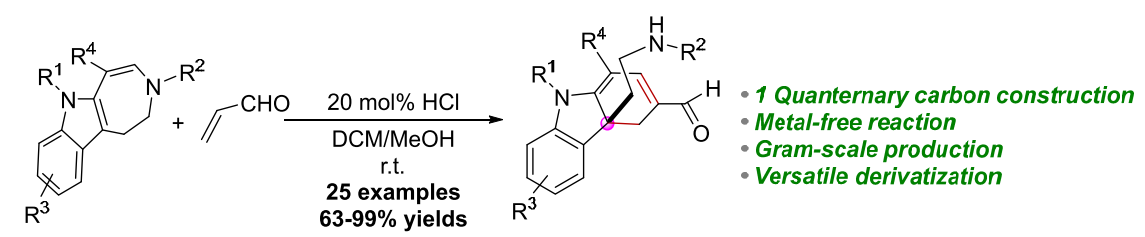

ABSTRACT: A unique approach to hydrocarbazoles bearing an all-carbon quaternary center at C4a position was developed via a Brønsted acid-initiated Diels-Alder cycloaddition/retro-Michael addition cascade process from facilely prepared azepino[4,5- $b]$ indoles and commercially available acrolein. The method provided a range of hydrocarbazoles in good to excellent yields. The practicality of this transformation was demonstrated by scale-up experiment and various transformations to several hydrocarbazole derivatives.

Hydrocarbazoles with an all-carbon quaternary center at $\mathrm{C} 4 \mathrm{a}$ position are the core frameworks existing in a variety of natural indole alkaloids and bioactive molecules. ${ }^{1}$ Some of these molecules have attracted much attention from medicinal chemists and synthetic chemists on account of their various bioactivities and highly structural diversity. ${ }^{2-4}$ For example, Wang and coworkers have developed a series of lead compounds bearing hydrocarbazole skeletons as resistance-modifying agents (RMAs) against methicillin-resistant Staphylococcus aureus (MRSA) that could selectively potentiate many $\beta$-lactam antibiotics (Of1) ${ }^{3 \mathrm{a}-3 \mathrm{~d}}$ and as anti-bacterial agent against both methicillin-susceptible Staphylococcus aureus (MSSA) and MRSA $(\mathrm{Of} 4)^{4}$. Recently, $\mathrm{Zu}$ and coworkers also reported the enantioselective syntheses of simplified leads of Of1 and their function in potentiating $\beta$-lactam antibiotics ${ }^{3 e}$ (Figure 1).

In the past few years, due to the importance of assembly of the hydrocarbazoles bearing an all-carbon quaternary center at C4a position, many elegant synthetic strategies have been developed on the basis of dearomative cyclization, ${ }^{2 \mathrm{e}-2 \mathrm{f}, 5}$ Heck cyclization, ${ }^{6}$ Fischer indolization, ${ }^{7}$ aza-Michael addition ${ }^{8}$ and cycloaddition of indole derivatives (Scheme 1). ${ }^{9}$ Although these efforts have greatly enriched the toolbox for the construction of hydrocarbazoles, the development of an expeditious and efficient strategy for the preparation of compounds bearing hydrocarbazole scaffolds is urgently in need to develop more potent bioactive molecules. Previously we developed a strategy for the syntheses of azepino[4,5- $b]$ indoles via cycloisomerization of

tryptamine-ynamides. ${ }^{10 b}$ The azepino[4,5-b]indoles contain diene moiety in their structures therefore they could serve as a diene component for [4 +2$]$ cycloaddition to generate hydrocarbazoles. In this study, a Diels-Alder cycloaddition/retro-Michael addition cascade strategy was developed aiming for the

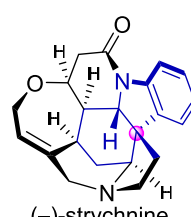

(-)-strychnine

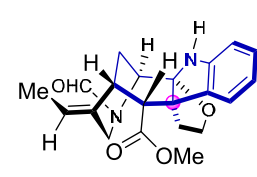

(-)-aspidophylline

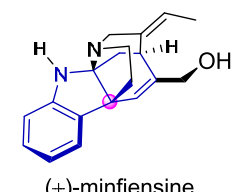

(+)-minfiensine

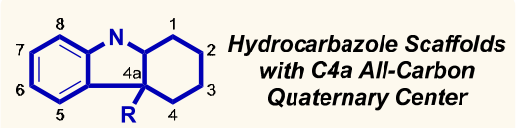

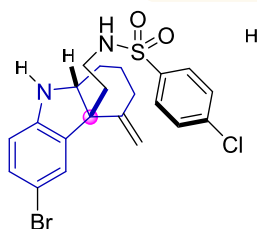

Of1, Wang's lead antibiotic adjuvant

Figure 1. Repres

\footnotetext{
Lead Compounds.
}

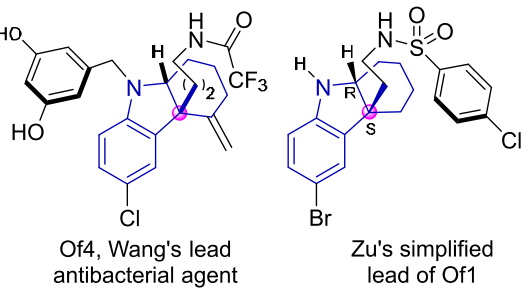
antibacterial agent 
preparation of hydrocarbazole scaffolds as a key molecular motif in natural products and potent RMAs. It was envisioned that a Diels-Alder cycloaddition of facilely prepared azepino[4,5$b$ ]indoles A and commercially available dienophiles B would provide the highly congested tetracyclic intermediate $\mathrm{C}$, followed by a sequent retro-Michael addition to release the strain of endocyclic structure to yield hydrocarbazole $\mathrm{E}$ after isomerization of intermediate D (Scheme 1).

Scheme 1. Representative Methods and Our Cascade Cyclization Strategy to Hydrocarbazoles

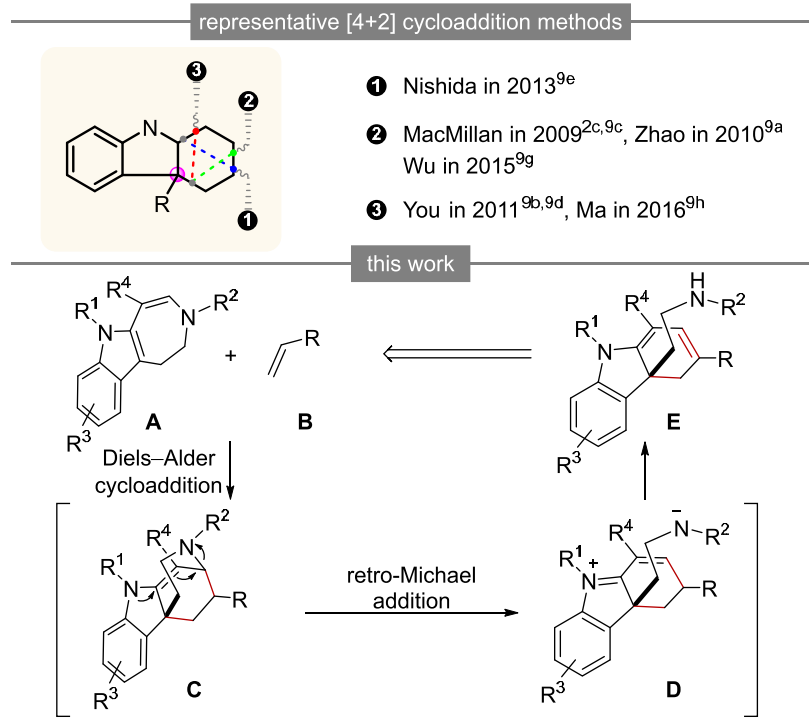

We began the investigation with azepino[4,5-b]indole $\mathbf{1}$ as the model substrate, which was easily synthesized by following our previous procedures. ${ }^{10 \mathrm{~b}}$ To our delight, when azepino[4,5$b$ ]indole 1 and acrolein 2 ( 3 equivalents) were treated with catalytic hydrochloric acid [20 mol\%, $1 \mathrm{~N} \mathrm{HCl}(\mathrm{aq})]$ in dichloromethane (DCM) at room temperature for $10 \mathrm{~h}$, the proposed cascade process happened as expected, affording the desired hydrocarbazole product 3 in a yield of 16\% (Table 1, entry 1). The structure of product 3 was determined by NMR spectroscopy and single-crystal X-ray diffraction (Table 1). This promising result prompted us to examine the parameters of the cascade process. First, different solvents such as methanol $(\mathrm{MeOH})$, $\mathrm{H}_{2} \mathrm{O}$, tetrahydrofuran (THF), acetonitrile $\left(\mathrm{CH}_{3} \mathrm{CN}\right)$ and toluene were screened under the catalysis of $20 \mathrm{~mol} \% \mathrm{HCl}$. However, no obvious improvement in yield was observed (Table 1, entries 2-6). It was rationalized that the low yield might result from the heterogeneity of the reaction in those solvents. To address this issue, the mixed solvent system was considered in the following screening of conditions. ${ }^{11}$ Fortunately, a combination of DCM and $\mathrm{MeOH}$ in a ratio of $3: 1(\mathrm{v} / \mathrm{v})$ was proved to be the best to this transformation (Table 1, entry 7). Next, screening of catalysts based on the optimal solvent system revealed that $\mathrm{HCl}$ was superior to other catalysts such as hydrobromic acid ( $\mathrm{HBr})$, trifluoroacetic acid (TFA), tribromoacetic acid (TBA), acetic acid $(\mathrm{AcOH}), p$-toluenesulfonic acid (PTSA), ytterbium trifluoromethanesulfonate $\left[\mathrm{Yb}(\mathrm{OTf})_{3}\right]$ and zinc chloride $\left(\mathrm{ZnCl}_{2}\right)$ (Table 1, entries 8-14). Blank control experiment without any catalyst gave no product, indicating that a Brønsted acid was essential to this transformation (Table 1, entry 15). Investigation on the amounts of acrolein showed that 3 equivalents of acrolein afforded the most satisfactory result (Table 1, entries 16-17). Decreasing the catalyst loading to $10 \mathrm{~mol} \%$ led to a lower yield of the desired product and increasing the catalyst loading to $30 \mathrm{~mol} \%$ gave no obvious improvement in yield (Table 1, entries 18-19).
Overall, the optimal conditions of this cascade transformation were determined as stirring the azepino $[4,5-b]$ indoles and acrolein (3 equivalents) under the catalysis of $20 \mathrm{~mol} \% \mathrm{HCl}$ in $\mathrm{DCM} / \mathrm{MeOH}(3: 1 \mathrm{v} / \mathrm{v})$ at room temperature for $10 \mathrm{~h}$.

Table 1. Optimization of Reaction Conditions ${ }^{a}$

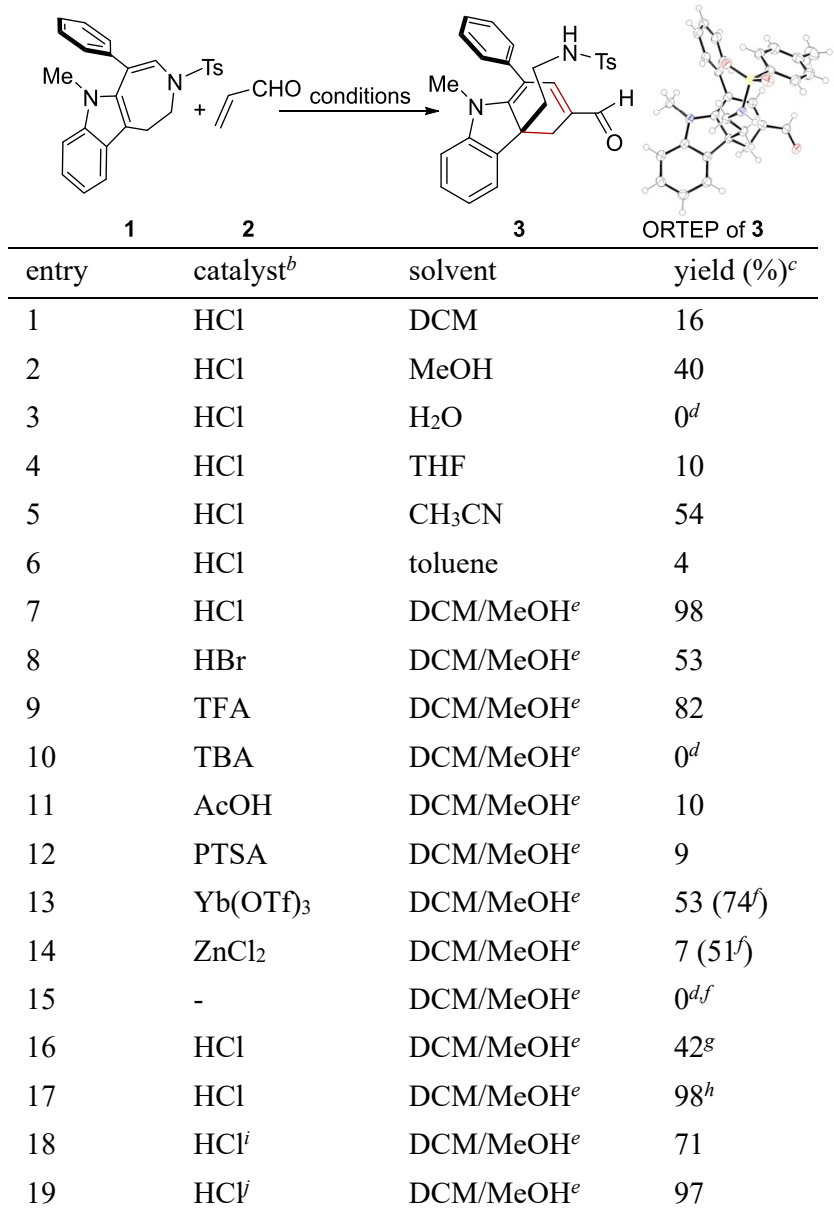

${ }^{a}$ Reaction was run at room temperature with 3 equiv. of acrolein. ${ }^{b} 20 \mathrm{~mol} \%$ catalyst was used in specified solvent $(0.03 \mathrm{M}) .{ }^{c}$ Isolated yields. ${ }^{d}$ Stirring for $48 \mathrm{~h} .{ }^{e} \mathrm{DCM} / \mathrm{MeOH}=3: 1(\mathrm{v} / \mathrm{v}) .{ }^{f}$ Stirring at $50{ }^{\circ} \mathrm{C}$ in sealed tube. ${ }^{g} 1$ equiv. of acrolein was used. ${ }^{h} 5$ equiv. of acrolein was used. ${ }^{i} 10 \mathrm{~mol} \%$ catalyst was used. ${ }^{j} 30 \mathrm{~mol} \%$ catalyst was used.

Under the optimal reaction conditions, various azepino[4,5$b$ ]indoles were synthesized to examine the scope of this cascade reaction. Investigation on the substitutions of indolic nitrogen revealed that the substrates with $\mathrm{Bn}$ and $\mathrm{PMB}$ substitutions gave excellent yields, however, the substrate with no protecting group on nitrogen afforded the product with a relatively lower yield probably due to the instability of the product during isolation (Scheme 2, 3a-3c). The examination of protecting groups on the nitrogen of the azepino core demonstrated that strong electron-withdrawing groups would facilitate the reaction (Scheme 2, 3d-3e). Furthermore, the substrates with different substituents on the indole ring were examined. It was found that the electronic nature of the substituents had little influence on the yields of this reaction (Scheme 2, 3f-3j). The scope of substituents on diene motif $\left(\mathrm{R}^{4}\right)$ was also examined. The substrates with different aryl groups underwent smoothly to give the hydrocarbazole products in satisfactory yields (Scheme 2, 3k-3t). The steric hindrance caused by meta-methoxyl and orthochloro substituents resulted in slightly lower yields of $\mathbf{3 s}$ and $3 t$. 
This reaction was also extended to the substrates with heteroaryl or alkyl groups on the azepino core, which provided the target molecules in almost quantitative yields (Scheme 2, 3u-3v). Finally, azepino[4,5- $b]$ indoles with alkyl-substituted diene motif were investigated. Different protecting groups on indolic and azepino nitrogens were well-tolerated, thus allowing the facile synthesis of hydrocarbazole products in acceptable yields

Scheme 2. Generality of Diels-Alder Cycloaddition/RetroMichael Addition Cascade Process ${ }^{a, b}$

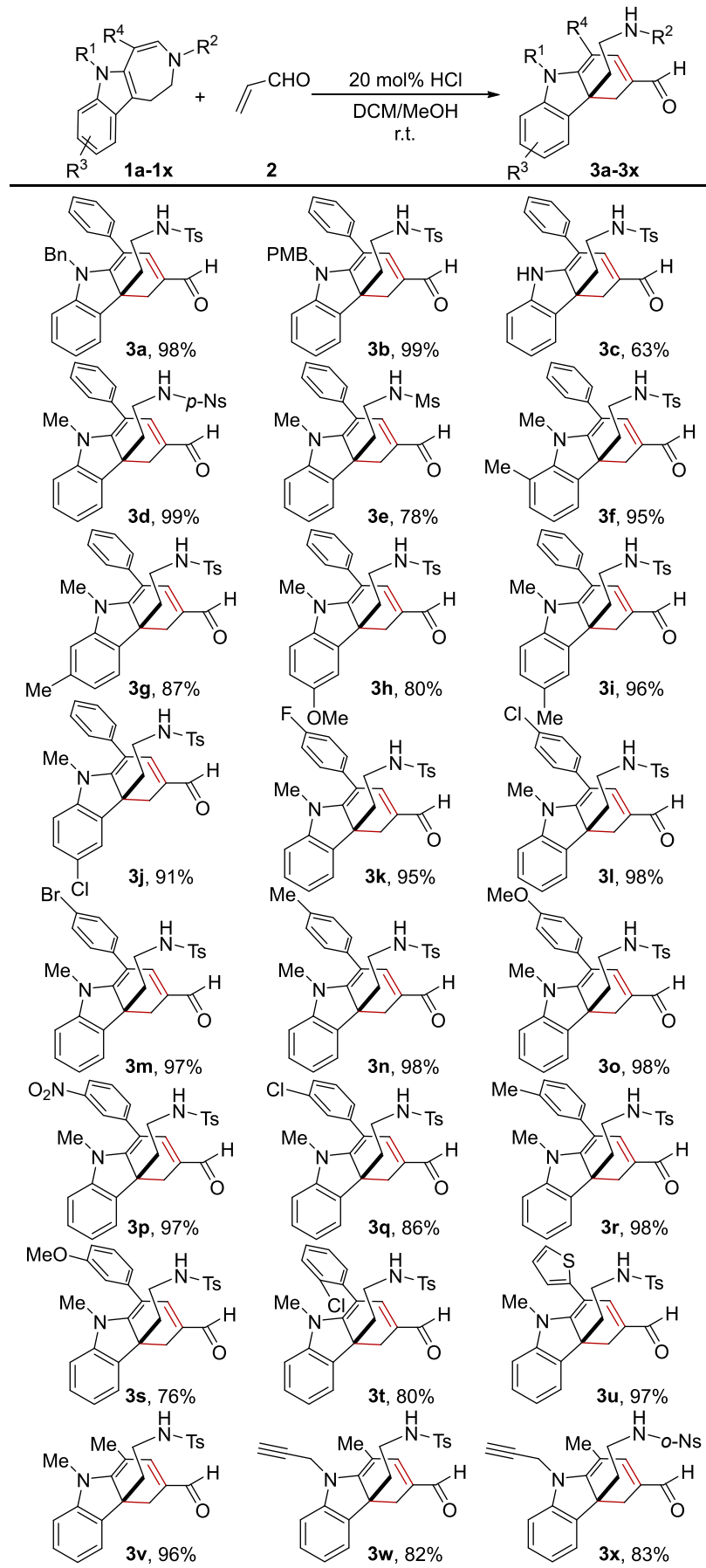

${ }^{a}$ Performed with $\mathbf{2 a - 2 \times}(1.0 \mathrm{mmol})$ and $\mathbf{1}(3.0 \mathrm{mmol})$ in the presence of a catalytic amount of $\mathrm{HCl}(1 \mathrm{~N} \mathrm{HCl}, 0.2 \mathrm{mmol})$ in $\mathrm{DCM} / \mathrm{MeOH}(3: 1 \mathrm{v} / \mathrm{v}, 7 \mathrm{~mL})$ at room temperature. The yields refer to the isolated products. ${ }^{b} \mathrm{Ts}=p$-toluenesulfonyl, $p$-Ns $=4$-nitrobenzenesulfonyl, $\mathrm{Ms}=$ methanesulfonyl, $o-\mathrm{Ns}=2$-nitrobenzenesulfonyl, $\mathrm{Bn}=$ benzyl, $\mathrm{PMB}=p$-methoxybenzyl.
(Scheme 2, 3w-3x).

To demonstrate the practicality of this robust methodology, scale-up synthesis using substrate $\mathbf{2}$ was performed, affording the hydrocarbazole product 3 in $80 \%$ yield. The following derivatizations were then attempted to explore the synthetic application of the product 3 by modifying the reactive aldehyde and sulfonamide moieties (Scheme 3 ). The Wittig reaction of product 3 underwent smoothly in toluene at $50{ }^{\circ} \mathrm{C}$, providing the highly conjugated ester derivatives in a yield of $90 \%$. The aldehyde moiety could also be transformed into unsaturated nitro compound by treating with nitromethane under the catalysis of ammonium acetate. In terms of the modification of the sulfonamide, a copper-catalyzed cross-coupling reaction of product $\mathbf{3}$ with phenylbromoethyne proceeded well to give versatile ynamide scaffold in $88 \%$ yield. Under basic condition, a propargyl group was readily introduced to the product $\mathbf{3}$ via a nucleophilic substitution. Such transformations demonstrated the versatile applications of the methodology.

Scheme 3. Scale-Up Experiment and Further Derivatization of $3^{a}$

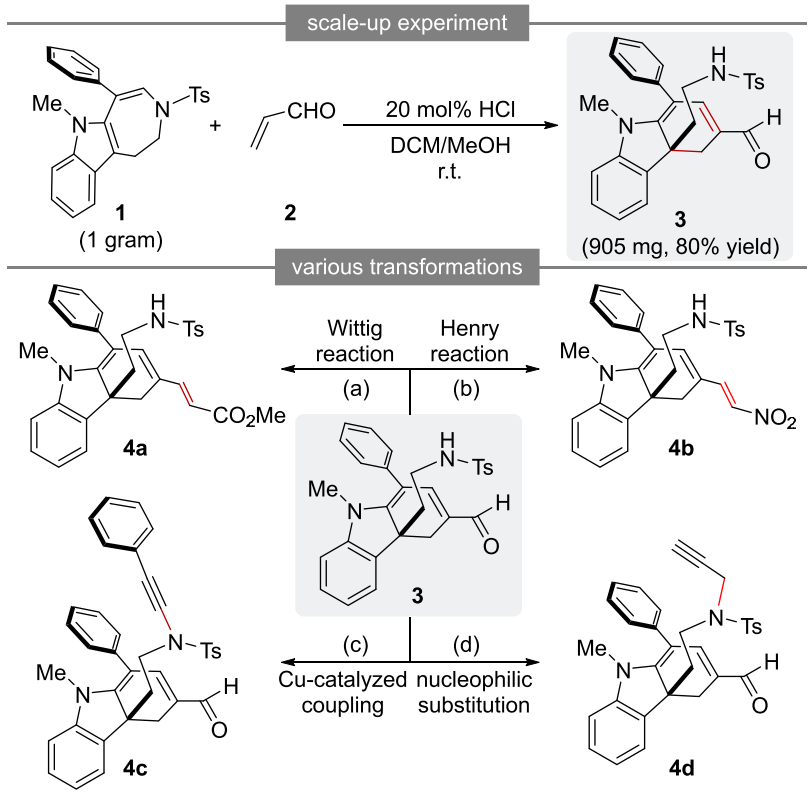

${ }^{a}$ Reagent and conditions: (a) $\mathrm{Ph}_{3} \mathrm{PCHCO}_{2} \mathrm{Me}$, toluene, $50{ }^{\circ} \mathrm{C}, 18 \mathrm{~h}$, $90 \%$; (b) $\mathrm{NH}_{4} \mathrm{OAc}, \mathrm{CH}_{3} \mathrm{NO}_{2}, 100^{\circ} \mathrm{C}, 15 \mathrm{~h}, 93 \%$; (c) phenylbromoethyne, $\mathrm{CuSO}_{4} \cdot 5 \mathrm{H}_{2} \mathrm{O}, \mathrm{Cs}_{2} \mathrm{CO}_{3}, 1,10$-phenanthroline, toluene, $90{ }^{\circ} \mathrm{C}$, 12 h, 88\%; (d) NaH, propargyl bromide, THF, 0 r.t., $91 \%$.

In conclusion, a robust Brønsted acid-initiated Diels-Alder cycloaddition/retro-Michael addition cascade strategy from azepino[4,5- $b]$ indoles and acrolein was developed. This methodology provided a facile entry to a series of hydrocarbazole derivatives bearing an all-carbon quaternary center at $\mathrm{C} 4 \mathrm{a}$ position with a wide functional group tolerance. The synthetic utility of the current method was exemplified by scale-up experiment and various derivatizations. It is expected that the methodology is of great use in development of bioactive hydrocarbazole analogs as well as total syntheses of complex natural products with hydrocarbazole scaffolds.

\section{ASSOCIATED CONTENT}

\section{Supporting Information}

The Supporting Information is available free of charge on the ACS Publications website. 
Experimental procedures, $\mathrm{X}$-ray single crystal analyses, compound characterization data (PDF)

\section{AUTHOR INFORMATION}

\section{Corresponding Author}

*E-mail: yongxiang.liu@syphu.edu.cn

\section{Author Contributions}

All authors have given approval to the final version of the manuscript.

\section{Notes}

The authors declare no competing financial interest.

\section{ACKNOWLEDGMENT}

Y. Liu thanked the financial support by the Natural Science Foundation of China (Grants 21977073), Liaoning Revitalization Talents Program and Liaoning BaiQianWan Talents Program. The authors acknowledged the program for the innovative research team of the Ministry of Education and the program for the Liaoning innovative research team in university.

\section{REFERENCES}

(1) (a) O'Connor, S. E. In Comprehensive Natural Products II; Mander, L., Liu, H.-W., Eds.; Elsevier: Amsterdam, 2010; Vol. 1, p 977. (b) Dictionary of Alkaloids, 2nd ed.; Buckingham, J., Baggaley, K. H., Roberts, A. D., Szabo, L. F., Eds.; CRC Press: Boca Raton, FL, 2010.

(2) For selected examples on bioactivity studies of the related alkaloids, see: (a) Ramirez, A.; Garcia-Rubio, S. Current Progress in the Chemistry and Pharmacology of Akuammiline Alkaloids. Curr. Med. Chem. 2003, 10, 1891-1915. For selected examples and reviews on synthetic studies of the related alkaloids, see: (b) Bonjoch, J.; Sole, D. Synthesis of Strychnine. Chem. Rev. 2000, 100, 3455-3482. (c) Jones, S. B.; Simmons, B.; MacMillan, D. W. Nine-Step Enantioselective Total Synthesis of (+)-Minfiensine. J. Am. Chem. Soc. 2009, 131, 13606-13607. (d) Zu, L.; Boal, B. W.; Garg, N. K. Total Synthesis of ( \pm )-Aspidophylline A. J. Am. Chem. Soc. 2011, 133, 8877-8879. (e) Zhang, Z. X.; Chen, S. C.; Jiao, L. Total Synthesis of (+)-Minfiensine: Construction of the Tetracyclic Core Structure by an Asymmetric Cascade Cyclization. Angew. Chem., Int. Ed. 2016, 55, 8090-8094. (f) Du, K.; Yang, H.; Guo, P.; Feng, L.; Xu, G.; Zhou, Q.; Chung, L. W.; Tang, W. Efficient Syntheses of (-)-Crinine and (-)-Aspidospermidine, and the Formal Synthesis of (-)-Minfiensine by Enantioselective Intramolecular Dearomative Cyclization. Chem. Sci. 2017, 8, 62476256.

(3) For selected examples on synthetic and bioactivity studies of the RMAs bearing hydrocarbazole scaffolds, see: (a) Podoll, J. D.; Liu, Y.; Chang, L.; Walls, S.; Wang, W.; Wang, X. Bio-Inspired Synthesis Yields a Tricyclic Indoline that Selectively Resensitizes MethicillinResistant Staphylococcus aureus (MRSA) to $\beta$-Lactam Antibiotics. Proc. Natl. Acad. Sci. USA 2013, 110, 15573-15578. (b) Chang, L.; Podoll, J. D.; Wang, W.; Walls, S.; O'Rourke, C. P.; Wang, X. Structure-Activity Relationship Studies of the Tricyclic Indoline Resistance-Modifying Agent. J. Med. Chem. 2014, 57, 3803-3817. (c) Xu, W.; Wang, W.; Wang, X. Gold-Catalyzed Cyclization Leads to a Bridged Tetracyclic Indolenine that Represses $\beta$-Lactam Resistance. Angew. Chem., Int. Ed. 2015, 54, 9546-9549. (d) Zhu, Y.; Cleaver, L.; Wang, W.; Podoll, J. D.; Walls, S.; Jolly, A.; Wang, X. Tetracyclic Indolines as a Novel Class of $\beta$-Lactam-Selective ResistanceModifying Agent for MRSA. Eur. J. Med. Chem. 2017, 125, 130-142. (e) Yu, Y.; Li, J.; Jiang, L.; Zhang, J. R.; Zu, L. Catalytic Enantioselective Aza-pinacol Rearrangement. Angew. Chem., Int. Ed. 2017, 56, 9217-9221.

(4) Michael Barbour, P.; Podoll, J. D.; Marholz, L. J.; Wang, X. Discovery and Initial Structure-Activity Relationships of $N$-Benzyl Tricyclic Indolines as Antibacterials for Methicillin-Resistant Staphylococcus aureus. Bioorg. Med. Chem. Lett. 2014, 24, 5602-5605.

(5) For selected examples on dearomative cyclization, see: Hosoya, K.; Iida, K.; Odagi, M.; Nagasawa, K. Synthesis of Hydrocarbazole Derivatives by Oxidative Dearomative Cyclization of Diarylamines
Using a Hypervalent Iodine Reagent. J. Org. Chem. 2020, 85, 1198011988

(6) For selected examples on Heck cyclization, see: (a) Dounay, A B.; Overman, L. E.; Wrobleski, A. D. Sequential Catalytic Asymmetric Heck-Iminium Ion Cyclization: Enantioselective Total Synthesis of the Strychnos Alkaloid Minfiensine. J. Am. Chem. Soc. 2005, 127, 1018610187. (b) Dounay, A. B.; Humphreys, P. G.; Overman, L. E.; Wrobleski, A. D. Total Synthesis of the Strychnos Alkaloid (+)Minfiensine: Tandem Enantioselective Intramolecular Heck-Iminium Ion Cyclization. J. Am. Chem. Soc. 2008, 130, 5368-5377. (c) GarciaFortanet, J.; Kessler, F.; Buchwald, S. L. Palladium-Catalyzed Asymmetric Dearomatization of Naphthalene Derivatives. J. Am. Chem. Soc. 2009, 131, 6676-6677.

(7) For selected examples on Fischer indolization, see: Martinez, A.; Webber, M. J.; Muller, S.; List, B. Versatile Access to Chiral Indolines by Catalytic Asymmetric Fischer Indolization. Angew. Chem., Int. Ed. 2013, 52, 9486-9490.

(8) For selected examples on aza-Michael addition, see: (a) Hyde, A. M.; Buchwald, S. L. Palladium-Catalyzed $\gamma$-Arylation of $\beta, \gamma-$ Unsaturated Ketones: Application to a One-Pot Synthesis of Tricyclic Indolines. Angew. Chem., Int. Ed. 2008, 47, 177-180. (b) Du, J. Y. Zeng, C.; Han, X. J.; Qu, H.; Zhao, X. H.; An, X. T.; Fan, C. A Asymmetric Total Aynthesis of Apocynaceae Hydrocarbazole Alkaloids (+)-Deethylibophyllidine and (+)-Limaspermidine. $J$. Am. Chem. Soc. 2015, 137, 4267-4273.

(9) For selected examples on cycloaddition, see: (a) Zheng, C.; Lu, Y.; Zhang, J.; Chen, X.; Chai, Z.; Ma, W.; Zhao, G. The Enantioselective, Organocatalyzed Diels-Alder Reaction of 2Vinylindoles with $\alpha, \beta$-Unsaturated Aldehydes: an Efficient Route to Functionalized Tetrahydrocarbazoles. Chem. Eur. J. 2010, 16, 58535857. (b) Cai, Q.; Zheng, C.; Zhang, J. W.; You, S. L. Enantioselective Michael/Mannich Polycyclization Cascade of Indolyl Enones Catalyzed by Quinine-Derived Primary Amines. Angew. Chem., Int. Ed. 2011, 50, 8665-8669. (c) Jones, S. B.; Simmons, B.; Mastracchio, A.; MacMillan, D. W. Collective Synthesis of Natural Products by Means of Organocascade Catalysis. Nature 2011, 475, 183-188. (d) Cai, Q.; You, S. L. Organocatalyzed Enantioselective Formal $[4+2]$ Cycloaddition of 2,3-Disubstituted Indole and Methyl Vinyl Ketone Org. Lett. 2012, 14, 3040-3043. (e) Harada, S.; Morikawa, T.; Nishida, A. Chiral Holmium Complex-Catalyzed Diels-Alder Reaction of Silyloxyvinylindoles: Stereoselective Synthesis of Hydrocarbazoles. Org. Lett. 2013, 15, 5314-5317. (f) Huang, J.; Zhao, L.; Liu, Y.; Cao, $\mathrm{W}$.; $\mathrm{Wu}, \mathrm{X}$. Enantioselective Intermolecular Formal $[3+3]$ Cycloaddition of 2,3-Disubstituted Indoles with Acrolein. Org. Lett. 2013, 15, 4338-4341. (g) Guo, B.; Ge, L.; Huang, G.; Zhao, L.; Chen, J.; Cao, W.; Wu, X. Expedient Introduction of $\beta$-Methoxyacrylate Unit onto 3-Substituted Indoles and Application of the Resulting IndoleDienes in Organocascade toward Indolino-Polycyclics. Adv. Synth Catal. 2015, 357, 4013-4021. (h) Guo, B.; Huang, X.; Fu, C.; Ma, S Carbazoles from the $[4 \mathrm{C}+2 \mathrm{C}]$ Reaction of 2,3-Allenols with Indoles. Chem. Eur. J. 2016, 22, 18343-18348.

(10) Selected examples and our work on azepino[4,5- $b]$ indole syntheses, see: (a) Li, L.; Chen, X.-M.; Wang, Z.-S.; Zhou, B.; Liu, X.; Lu, X.; Ye, L.-W. Reversal of Regioselectivity in Catalytic AreneYnamide Cyclization: Direct Synthesis of Valuable Azepino[4,5 $b$ ]indoles and $\beta$-Carbolines and DFT Calculations. ACS Catal. 2017, 7 , 4004-4010. (b) Pang, Y.; Liang, G.; Xie, F.; Hu, H.; Du, C.; Zhang, X Cheng, M.; Lin, B.; Liu, Y. N-Fluorobenzenesulfonimide as a Highly Effective Ag(I)-Catalyst Attenuator for Tryptamine-Derived Ynesulfonamide Cycloisomerization. Org. Biomol. Chem. 2019, 17, 2247-2257.

(11) (a) Austin, J. F.; MacMillan, D. W. Enantioselective Organocatalytic Indole Alkylations. Design of a New and Highly Effective Chiral Amine for Iminium Catalysis. J. Am. Chem. Soc. 2002, 124, 1172-1173. (b) Jin, J.; Qiu, F. G. Total Synthesis of ( \pm )-1Acetylaspidoalbidine and $( \pm)-1-$ Methylaspidospermidine. Adv. Synth. Catal. 2014, 356, 340-346. 